\title{
An unusual wig masquerading as calcific
}

\section{neurocysticercosis}

\section{WFC van Gelderen} FFRad(D)(SA)

Consultant Radiologist, Taranaki Base Hospital, New Zealand

\begin{abstract}
A
26-year-old black woman, who had been involved in a motor vehicle accident, was referred for radiography of the skull (Figure 1). $\mathrm{X}$-rays did not demonstrate any signs of bony injury, but did reveal multiple rounded opacities related to the cranial vault, initially thought possibly to be due to calcific neurocysticercosis or alternatively multiple sclerotic bony
\end{abstract} metastases.

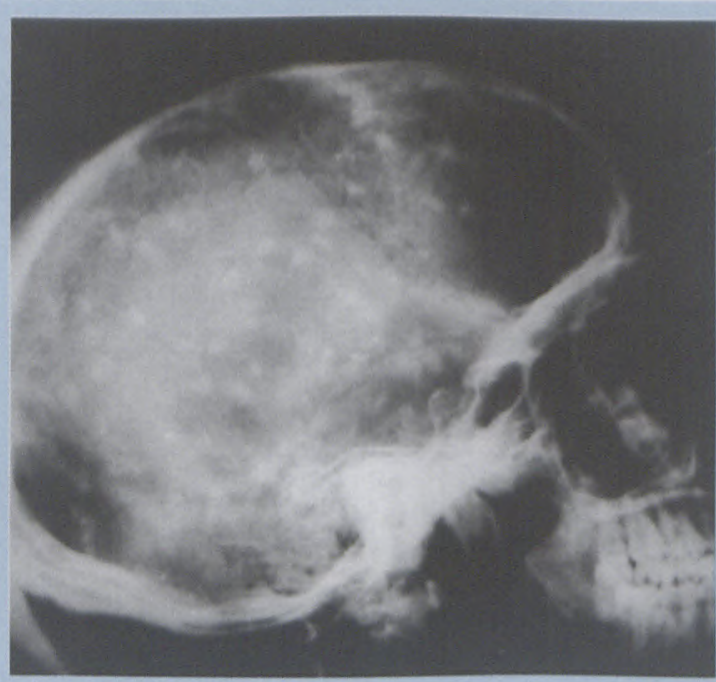

Figure 1: Lateral radiograph of the skull demonstrating multiple small opacities simulating calcific neurocysticercosis but due to tufts of hair within a wig seen end-on.
When the patient was examined clinically by the reporting radiologist, she was found to be wearing a most impressive and very realistic black wig with strands of hair woven around small hooks within the confines of the wig. These small hooks, containing tight knots of hair, were responsible for the multiple cranial opacities when seen end-on.

\section{AMA/PRA Category 1 Accredited Course Category A CE (ASRT) Accredited Course 1999 CMRS Annual Society Meeting}

DATE: June 24-27, 1999

VENUE: Disney's Yacht \& Beach Club Resorts. Lake Buena Vista, Florida, USA TOPIC: Clinical Magnetic Resonance Imaging

ATTENDEES: Physicians and Radiologic Technologists TECHNICAL EXHIBITS
CONTACT:

Caren Theuring

Clinical Magnetic Resonance Society 800-823-2677, 513-221-0070

Fax: 513-221-0825

Email: cmrs@one.net 